\title{
COORDENAÇÃO PEDAGÓGICA: ASPECTOS E RELAÇÕES ESSENCIAIS NA EDUCAÇÃO
}

\author{
PEDAGOGICAL COORDINATION: ESSENTIAL ASPECTS AND \\ RELATIONSHIPS IN EDUCATION
}

\author{
Marcelane Aparecida Ferreira ${ }^{1}$ \\ Marcelane.ferreira3@gmail.com
}

\section{RESUMO}

O propósito do artigo é compreender a verdadeira função do coordenador pedagógico, buscando a construção de sua identidade profissional, direcionado seu verdadeiro papel de formador na instituição pela qual atua. Nele aborda-se que o coordenador pedagógico anseia por alcançar de fato sua verdadeira função dentro do ambiente escolar. Esta pesquisa parte da inquietação gerada quando questionado se a partir da legislação vigente são realmente amparados os anseios de atuação do coordenador pedagógico dentro das instituições em que atuam, e se as condições em que trabalham são suficientes para 0 exercício de seu papel fundamental como formador de educadores? A pesquisa tem como objetivo geral compreender a verdadeira função do coordenador pedagógico, buscando a construção de sua identidade profissional, direcionado seu verdadeiro papel de formador na instituição por qual atua. Através da lei que o caracteriza ser um elemento fundamental dentro da escola, e se tem conseguido dar uma nova versão pra a educação na escola. O coordenador pedagógico a necessita de uma gama de saberes para atuar conscientemente nas diversas situações que permeiam o espaço escolar, dentre elas destacamos o processo ensino/aprendizagem; o desenvolvimento, implantação e implementação do Projeto Político Pedagógico da Escola; a formação de professores; a utilização de métodos/estratégias e recursos pedagógicos mais adequados para o desenvolvimento dos alunos e a promoção de ações que contribuem para o equilíbrio das relações interpessoais. Nesse contexto, salientamos que o domínio desses e de muitos outros saberes, torna o coordenador pedagógico hábil para intervir em situações diversas no seu cotidiano escolar.

Palavras chaves: Coordenação Pedagógica, Funções, Desafios, Formador.

\section{ABSTRACT}

The purpose of the article is to understand the true function of the pedagogical coordinator, seeking the construction of his/her professional identity, directed to his true role as a trainer in the institution for which he operates. It discusses that the pedagogical coordinator longs to achieve his true function within the school environment. This research is part of the concern generated when asked

\footnotetext{
${ }^{1}$ Pedagoga, Letrada, Pós graduada em Gestão Educacional, Mestre em ciências da Educação pela
} Universidade Gama Filho-RJ (Brasil) 
whether from the current legislation are really based on the pedagogical coordinator's thesis of action within the institutions in which they work, and whether the conditions in which they work are sufficient to exercise their fundamental role as a trainer of educators? The research has as general objective to understand the true function of the pedagogical coordinator, seeking the construction of his professional identity, directed his true role as a trainer in the institution for which he operates. Through the law that characterizes it to be a fundamental element within the school and has been able to give a latest version to education in school. The pedagogical coordinator needs a range of knowledge to act consciously in the various situations that permeate the school space, among them we highlight the teaching/learning process; the development, implementation and implementation of the School's Pedagogical Political Project; teacher training; the use of pedagogical methods/strategies and resources more appropriate for the development of students and the promotion of actions that contribute to the balance of interpersonal relationships. In this context, we emphasize that the proficiency in these and much other knowledges makes the pedagogical coordinator able to intervene in different situations in his school life.

Keywords: Pedagogical Coordination, Functions, Challenges, Trainer.

\section{INTRODUÇÃO}

O presente artigo é elaborado a partir da inquietação gerada quando questionado se a partir da legislação vigente são realmente amparados os anseios de atuação do coordenador pedagógico dentro das instituições em que atuam, e se as condições em que trabalham são suficientes para o exercício de seu papel fundamental como formador de educadores?E assim auxiliar de forma conjunta o seu gestor e equipe educacional, analisando profundamente o papel do coordenador pedagógico dentro da educação, voltada para a formação do grupo docente para uma melhor qualidade de ensino aos seus alunos. Também buscar maneiras pelas quais ele possa estar atuando eficazmente, trazendo para dentro da escola um ambiente mais harmonioso.

Para tanto, faremos um estudo bibliográfico o qual procura explicar um problema a partir de referências teóricas publicadas em documentos, fato que se configurará parte essencial de nossa pesquisa, haja vista que ela se fundamenta, em primeira instancia, na análise das Leis já promulgadas, que instituem as políticas públicas para a educação por auxílio deste profissional, que trabalham nessa vertente de estudo. Sobrequais as melhores formas de trabalho com o ser humano, sendo eles alunos, professores, pais, diretores e 
os demais funcionários que atuam na escola, pois cada um desempenha um papel fundamental dentro da instituição. Pretendemos para tanto, analisar se a efetivação deste profissional, que de certa forma acaba fazendo o que não é de sua verdadeira função, até mesmo por não saber direito qual ela é, se tem conseguido alcançar o objetivo de ser um bom formador, analisando ainda se as diretrizes educacionais vêm amparando nos problemas surgidos dentro da escola. Para tanto especificamos a seguir nosso objetivo geral e específico desta pesquisa.

A pesquisa tem como objetivo geral compreender a verdadeira função do coordenador pedagógico, buscando a construção de sua identidade profissional, direcionado seu verdadeiro papel de formador na instituição pela qual atua. De forma objetiva pretende-se: identificar o perfil do coordenador pedagógico; analisar as contribuições do Coordenador pedagógico no âmbito educacional e analisar as práticas dos coordenadores pedagógicos e seu ajustamento e ou desajustamento às prescrições legais.

Do ponto de vista metodológico a pesquisa, a pesquisa consiste no levantamento da literatura pertinente ao tema. Contextualiza-se o objeto de estudo, em seguida faz-se a coleta dos dados e finamente analisa-se os dados encontrados na literatura. Os discernimentos oriundos da elaboração do conhecimento acadêmico estão ancorados na importância de conhecer como se inicia uma pesquisa científica é um ponto de fundamental importância nas investigações. Existem variantes significantes a considerar durante este processo duradouro, e mesmo com as dificuldades no caminho da pesquisa científica, de conhecer suas etapas, de entender os quesitos válidos, necessário se ter sabedoria para superar as dificuldades que aparecem no transcorrer do caminho. Neste sentido a definição do problema de pesquisa é uma etapa que inicialmente pode parecer simples e tranquila, mas no transcorrer do caminho se apresenta com conhecimentos complexos.

A palavra "problema" conforme conceitua o Dicionário Aurélio tem como significado, dentre os demais contidos, o de ser uma "questão não solvida e que é desejo de discussão, em qualquer domínio do conhecimento". Segundo Gil (1991), nem todo problema é passível de tratamento científico, é preciso primeiramente identificar o que é científico daquilo que não é considerado. $\mathrm{E}$ 
neste sentido para ser científico precisa envolver variáveis que podem ser testáveis.

Segundo Gil (1991) o processo de formular um problema envolve uma gama de variáveis, que não podem, na maioria das vezes serem controladas, é o caso do fator criatividade.

O texto está estruturado em seções. A primeira discute Aspectos relevantes da coordenação pedagógica e suas relações no âmbito escolar. A segunda explora, o papel do coordenador pedagógico: compromissos e desafios na atualidade, a terceira dialoga com a concepções e o processo de constituição da identidade docente. Na quinta seção é elaborado, a multiplicidade das funções à crise identitária e mal-estar do profissional. $\mathrm{E}$ a última seção discute a constituição da identidade profissional do coordenador pedagógico no estado do Pará. E finalmente, as considerações finais.

\section{ASPECTOS RELEVANTES DA COORDENAÇÃO PEDAGÓGICA E SUAS RELAÇÕES NO ÂMBITO ESCOLAR.}

Entender as relações existentes no cotidiano escolar é um trabalho complexo, primeiramente pelos diversos meios de manifesto e segundamente pelos próprios organismos que permitam asua apreensão e compreensão. Sendo que quando estamos diante de uma instituição de ensino, trazemos com a gente uma série de conceitos pré-determinados, originários de nossas percepções dos acontecimentos vivenciados. E muitas vezes esses conceitos pré-estabelecidos acabam impedindo percepções de certas situações educacionais.

De acordo com as concepções de Libâneo, Oliveira e Toschi "o setor pedagógico compreende as atividades de coordenação pedagógica e de orientação educacional" (2003, p.342). Quando disponíveis nas instituições, ambos preocupam-se com a formação do aluno, porém, o coordenador possui relação direta e significativa com os professores, e o orientador possui relação direta com os alunos. Mas quando não disponíveis, cabe ao coordenador atuar com todas essas funções.

Ainda para Libâneo et al (2003), o coordenador pedagógico tem a função de acompanhar, assessorar, apoiar e avaliar as atividades pedagógico- 
curriculares. Mas afunção principal do profissional, destacada pelos autores, diz respeito à assistência aos professores em seus respectivos componentes curriculares. Cabe também ao coordenador o relacionamento com pais e comunidade, conforme é destacado a seguir, no que se refere ao funcionamento pedagógico-curricular e didático da escola, à comunicação das avaliações dos alunos e à interpretação feita delas além de algumas outras atribuições, tais como:

[...] o acompanhamento das atividades de sala de aula, em atitude de colaboração como professor da classe; a supervisão da elaboração de diagnósticos, para o projeto pedagógico-curricular da escola e para outros planos e projetos; a orientação da organização curricular e o desenvolvimento do currículo, incluindo a assistência direta aos professores na elaboração dos planos de ensino, na escolha de livros didáticos, nas práticas de avaliação da aprendizagem; a coordenação de reuniões pedagógicas e de entrevistas com professores, para promover relação horizontal e vertical entre disciplinas, estimular a realização de projetos conjuntos entre os professores, diagnosticar problemas de ensino e aprendizagem, adotando medidas pedagógicas preventivas, e adequar conteúdos, metodologias e práticas avaliatórias; a proposição e a coordenação de atividades de formação continuada e de desenvolvimento profissional dos professores. (LIBÂNEO; OLIVEIRA; TOSCHI, 2003, p.374).

Tabela 1 - Atribuições do Coordenador Pedagógico

\begin{tabular}{|l|}
\hline - Coordenar os momentos de formação em serviço dos professores; \\
\hline - Participar junto com os professores do planejamento das atividades e \\
acompanha sua realização; \\
\hline - Observar aulas dos professores para ajudá-los no desenvolvimento das \\
atividades; \\
\hline - Realizar com os professores nas reuniões de pais; \\
\hline - Colaborar na elaboração do projeto político-pedagógico; \\
\hline - Cuidar para que o projeto seja cumprido no dia a dia; \\
\hline - Acompanhar e analisa junto com os professores o desempenho dos alunos; \\
\hline - Realizar, organizar e manter os registros do trabalho pedagógico; \\
\hline - Realizar reuniões regulares com o diretor para analisar as condições e o \\
processo de ensino e da aprendizagem; \\
\hline - Organizar junto aos professores a exposição das produções dos alunos; \\
\hline - Analisar e divulgar o acervo da escola.
\end{tabular}

Fonte: Secretaria da Educação do Estado de São Paulo apud POLATO (2010)

\section{A relação existente com a direção escolar.}

Segundo a concepção de Saviani (1996), o diretor "é o responsável máximo no âmbito da unidade escolar cujo papel poderia ser definido genericamente nos seguintes termos: garantir o bom funcionamento da escola" (p. 207). De forma geral, é o profissional responsável por administrar a 
instituição por meio de um conjunto de técnicas, processos e práticas administrativas, políticas e pedagógicas com vistas ao atendimento do ensino de qualidade.

Libâneo (2001), com base na descrição da escola realizada por Paro (2000), descreveas funções da direção:

O diretor coordena, organiza e gerencia todas as atividades da escola, auxiliado pelos demais componentes do corpo de especialistas e de técnico-administrativos, atendendo às leis, regulamentos e determinações dos órgãos superiores do sistema de ensino e às decisões no âmbito da escola e pela comunidade. $O$ assistente de diretor desempenha as mesmas funções na condição de substituto eventual do diretor. (LIBÂNEO, 2001, p.341)

Percebe-se, portanto, que o coordenador pedagógico adentra nessa perspectiva, relacionando-se diretamente com o diretor e tendo papel de auxiliar na organização das responsabilidades da instituição de ensino. Segundo Libâneo, Oliveira e Toschi, o diretor "possuía atribuições pedagógicas e administrativas próprias, e uma das mais importantes é a de gerir o processo de tomada de decisões por meio de práticas participativas"(2003, p.372). Mas para que isso aconteça segundo os autores, o diretor atua, em geral, mais diretamente nas funções administrativas, confiando os aspectos pedagógico a uma coordenação,a pedagógica.

$\mathrm{Na}$ perspectiva de Polato (2010) é ponderado que o coordenador pedagógico responde junto ao diretor, criando uma relação de parceria para transformar a escola no espaço adequado e organizado para a aprendizagem. Contudo, a autora destaca que o coordenador acaba assumindo funções administrativas, mesmo sem formação adequada. Abaixo listamos algumas atribuições delegadas ao diretor escolar, e que pela sua ausência, são exercidas pelo coordenador dentro de muitas instituições.

Tabela 2 - Atribuições do Diretor Escolar

\begin{tabular}{|l|}
\hline - Articular o relacionamento com a comunidade interna e externa; \\
\hline - Garantir o acesso ao acervo da escola. \\
\hline - Orientar a organização do espaço e assegura a exposição das produções dos \\
alunos; \\
\hline - Elaborar o cronograma e realiza reuniões regulares com os diferentes \\
segmentos da escola; \\
\hline - Articular a equipe para o planejamento e a realização das reuniões de pais; \\
\hline - Desenvolver projetos institucionais em parceria com coordenadores e equipe; \\
\hline - Levantar, analisar e acompanhar o desempenho dos alunos; \\
\hline - Cuidar do desenvolvimento dos profissionais;
\end{tabular}


- Assegurar e acompanha os momentos de planejamento e estudo da equipe;

- Garantir as condições para o cumprimento do projeto;

- Liderar a elaboração e revisão do projeto político-pedagógico;

- Assegurar, acompanhar e controlar recursos materiais e financeiros;

- Colaborar nas decisões da rede e concretiza as políticas públicas na escola;

- Responder pela escola (legalmente, judicialmente e pedagogicamente);

Fonte: Secretaria da Educação do Estado de São Paulo apud POLATO (2010)

\section{A relação existente entre o profissional e as famílias dos alunos.}

Desde a década de vinte, a pedagogia passou a ter mais acentuada as características básicas da psicologia, e desta forma coube ao coordenador pedagógico, antigo orientador educacional, a função de acompanhar, orientar e aconselhar as famílias dos alunos. Essa tarefa tornou-se essencial e perdura até aos dias atuais. E acredita Orsolon (2003) que a relação existente entre família e escola deva ser de parceria, confiança e cumplicidade. Da mesma forma, a autora destaca que para haver essa harmonia, é preciso que o coordenador pedagógico esteja atento a alguns aspectos relevantes na relação, dentre eles destaca:

\footnotetext{
- Conhecer o lugar social das famílias dos alunos;

- Compreender as diferentes configurações familiares e relacionar-se com elas sem preconceito;

- Identificar os modelos educativos que norteiam as ações educativas das famílias e da escola;

- Prever espaço para a participação da família na gestão escolar. (ORSOLON, 2003, p.182)
}

A socialização entre os coordenadores pedagógicos e a comunidade, para ser mais preciso, com as famílias dos alunos facilita a comunicação eos aproxima à escola. Entretanto, ainda cabe ao profissional procurar por estas parcerias em grande maioria das vezes. Quando pensamos em comunidade, no total, ele pode assumir a função de articulador no trabalho de integração entre a escola e a comunidade. Portanto, precisa ser reconhecido como a ligação direta de suma importância no relacionamento da comunidade com a instituição de ensino.

Portanto, o coordenador passou a executar as funções do orientador, assessorando as famílias na educação de seus filhos, enfatizando a importância do ambiente escolar para o crescimento intelectual, autônomo e crítico, vindos da relação entre o professor, coordenador e família. 


\title{
O PAPEL DO COORDENADOR PEDAGÓGICO: COMPROMISSOS E DESAFIOS NA ATUALIDADE.
}

Um dos domínios aos quais os especialistas internacionais dedicam mais atenção é a formação inicial e continuada de professores.

Um aspecto bastante discutido se deu com a antecipação da idade na alfabetização da criança e a obrigatoriedade do tempo de escolarização básica, pois aconteceram mudanças antes da aprovação da Lei № 11.274, que instituiu o ensino fundamental de nove anos no território nacional, sem direito a contestação e sem a devida preparação da comunidade escolar.

A rápida chegada da Lei o 11.274 provocou inquietações e ansiedade entre professores e gestores, que à primeira vista não se consideravam sujeitos capazes de produzir progressos nas condições de melhoria do processo ensino-aprendizagem devido a esta transformação. Nesta visão Schneider (2009) pondera que

\begin{abstract}
A ampliação do ensino fundamental veio de fora para dentro do ambiente escolar, desqualificando o professor da capacidade de compreensão de sua prática cotidiana e, em certa medida, produzindo estranhamento acerca de uma proposta na qual se espera que ele seja o protagonista. (SCHNEIDER, 2009, p.2).
\end{abstract}

Levando em considerando a identificação do professor com tamanhas mudanças ocorridas, houve a necessidade de promover reflexões acerca do novo desafio em que se constituiu a formação dos profissionais da educação.

O estudo de Geni Rosa Duarte "acredita que não seja possível mudar a forma de transmissão dos conhecimentos, sem se discutir antes as possibilidades e limites do próprio conhecimento que se lida"(2005, p. 52).

Algumas diretrizes apresentam objetivos voltados às exigências que 0 mundo do trabalho moderno e tecnológico colocam à educação. Os Parâmetros Curriculares Nacionais para o Ensino Médio - PCNEM apontam que "o desenvolvimento das competências cognitivas e culturais para o pleno desenvolvimento humano passa a coincidir com o que se espera na esfera da produção" (PCNEM, p.12). Segundo o documento torna-se necessário investir cada vez mais na formação docente, já que "as medidas sugeridas exigem mudanças na seleção, tratamento dos conteúdos e incorporação de instrumentos tecnológicos modernos, como a informática" (PCNEM, p.13), 
Dentre diversos objetivos propostos nas mais diversas áreas de conhecimento pelo PCNEM destacamos três que se referem a Ciências Humanas, que desejam como competência:

Entender os princípios das tecnologias associadas ao conhecimento do indivíduo, da sociedade e da cultura, entre as quais as de planejamento, organização, gestão e trabalho de equipe, e associálos aos problemas que se propõe resolver; entender o impacto das tecnologias associadas a ciências humanas sobre sua vida pessoal, os processos de produção, o desenvolvimento do conhecimento e a vida social; entender a importância das tecnologias contemporâneas de comunicação e informação para planejamento, aplicar as tecnologias das ciências humanas e sociais na escola, no trabalho e em outros contextos relevantes para sua vida (PCNEM, p.15).

O pedagogo escolar, além do papel de liderança no interior da escola, possui também poder de decisão que pode implementar algumas condições básicas para o desenvolvimento profissional docente. A organização do trabalho na escola, em seu entorno administrativo-pedagógico e burocrático da sala de aula - responsabilidade da equipe pedagógica pode influir favoravelmente ou não no processo de construção do saber fazer docente.

O pedagogo pode promover reuniões sistemáticas com profissionais envolvidos na escola (psicólogo, merendeira, recepcionista, bibliotecária, serventes, secretária etc.)para ouvi-los e orientá-los, visto que fazem parte da função educativa vivida nas instituições de ensino. Frequentemente eles observam atitudesdos alunos em espaços escolares que nem professores e pedagogos observam. Em grupo, podem estabelecer ações coletivas comuns no campo de formação de atitudes e valores junto aos alunos. Esse é um trabalho que deve estar previsto e articulado ao projeto político-pedagógico da escola.

A criação de uma instituição de ensino reflexiva é um ponto a ser considerado pelos profissionais envolvidos na educação. Alarcão (2001) considera que uma instituição assim concebida pensa no presente para mentalizar o que terá no futuro, mas é preciso resolver os problemas atuais visando "melhorias da educação praticada e para o desenvolvimento da organização" (2001, p.25).

Outros desafios enfrentados pelos coordenadores pedagógicos e que são destacadas para que haja um desempenho mais eficiente frente à resistência dos professores são as mudanças de atitude com os alunos, às 
resistências e dificuldades na formação continuada e aos desafios do coordenador pedagógico em auxiliar os professores a implantar as novas tecnologias.

Christov (2001) divulga fortes críticas à coordenadores em seu estudo de doutorado. A autora aponta que é extremamente necessário viabilizar oportunidades para que os professores percebam a importância de alguns aspectos na profissão, e que com isso consigam melhorar seu trabalho. Dentre as críticas apontamos:

- É preciso possibilitar que os professores analisem teorias de ensino e educação;

- Permita a elaboração das próprias teorias de ensino e educação;

- Auxilie na avaliação e planejamento das práticas docentes;

- Viver a experiência da divergência, sustentar a diferença entre concepções e situar seus modos de ver a escola, os alunos e a profissão.

Cabe, portanto, ao coordenador, apesar de ser uma ideia pretensiosa, aceitar coerentemente as concepções dos professores, retirando de sua mentalidade a concepção de que domina os conhecimentos pedagógicos muito mais do que os professores.

Em Garrido (2000) encontramos ideias sobre o desafio do coordenador pedagógico, apontando a complexidade existente na profissão. Considera que

\footnotetext{
Essas dificuldades por si só tornam compreensíveis as atitudes de resistência a mudança por parte dos professores. Elas se originam em grande parte do risco a que expõe o corpo docente e a instituição ao introduzirem novas práticas, que ainda não dominam, e cujos resultados no aluno são incertos. (GARRIDO, 2000, p,10)
}

\section{CONCEPÇÕES E O PROCESSO DE CONSTITUIÇÃO DA IDENTIDADE DOCENTE.}

Estudos realizados por André (2009) mostram que a produção científica sobre identidade docente, aumentou consideravelmente no período de 1999 a 2003. A autora aponta em seus estudos 1184 pesquisas sobre o processo de formação de professores, o que revela o crescente interesse sobre o tema. Sendo que desse total de estudos analisados, $13 \%$ abordam a perspectiva da identidade, que quando comparado com estudos em períodos anteriores 
evidenciam um aumento significante do interesse de estudiosos desse campo sobre a problemática da constituição da identidade docente.

Percebe-se entre os estudos, uma grande preocupação dos autores em chegar a um conceito final do que realmente é entendido como constituição de identidade. No caso de Ciampa (1987) fica entendida identidade como uma metamorfose, uma transformação, sendo o resultado temporário da união entre a história pessoal, seu contexto histórico e social e seus projetos. Afirma no mesmo estudo que a identidade tem caráter dinâmico e seu movimento pressupõe uma personagem.

Já em estudos feitos uma década depois, Dubar (1997) concebe identidade como resultado do processo de socialização, que compreende o cruzamento dos processos relacionais, mais precisamente da ação nos quais os indivíduos estão inseridos e o processo biográfico histórico, habilidades e projetos do indivíduo. E neste sentido de concepção o autor ainda pondera que a "identidade nunca é dada, é sempre construída e a (re) construir, em uma incerteza maior ou menor e mais ou menos durável” (Dubar, 1997, p. 104).

Noutra análise nesta temática Dubar (1997) considera a constituição das formas identitárias a partir de dois processos: um relacional e outro biográfico. Explica nos estudos que o processo relacional tem a ver com à identidade para o outro, onde as transações admitem um estilo mais objetivo e genérico. Já o processo biográfico corresponde à identidade para si, cujas ligações são mais subjetivas, individuais e compreende as identidades herdadas e identidades em vista.

Bauman (2005) procura definir identidade em seus estudos mais recentes como autodeterminação, ou seja, o eu postulado. O autor aponta que as identidades comumente referem-se às comunidades como sendo as entidades que as definem. À primeira vista, essa concepção apresenta características do pós-modernismo, sem identidade fixa, essencial ou permanente, transformada continuamente e que sofre influência das formas como é representada ou interpretada. Esta visão segundo Hall (2006), apresenta características positivas, pois da mesma forma que desestabiliza identidades estáveis do passado ela também abre possibilidade de desenvolvimento de novos sujeitos. 
Entre o período de 2005 e 2010 são expressas ideias de identidade como processo de constituição permanente, caracterizado por movimento de afirmação e negação. Ferreira (2006) analisa como o ser-professor se narra e interpreta-se como sujeito na profissão, tendo em vista compreender de que maneira esse profissional constrói a identidade pessoal/profissional, sendo capaz de afirmar-se ou negar-se como sujeito dentro do sistema-escola.

Da mesma forma, há autores que defendem que a identidade se constrói no processo de formação inicial, sobretudo na vivência da prática profissional. Neste sentido, Freitas (2006) relata e compreende como se constitui a identidade docente em processo de formação, destacando a prática como elemento influenciador e formador nas diferentes trajetórias de identidade. Em contrapartida há pressupostos de que a identidade também se constrói no processo de formação continuada desenvolvido na escola, Buccini (2007) indica que a constituição da identidade pessoal e profissional são etapas paralelas que deveriam ser preocupação da formação em exercício.

Soma-se a estas proposições o enfoque dado na profissionalização por Pandolpho (2006), reconhecendo e analisando aspectos identitários construídos e até mesmo reconstruídos ao longo do processo de profissionalização, este que percorre desde a escolha da profissão, a formação inicial, a inserção profissional e a práxis educacional.

\section{DA MULTIPLICIDADE DAS FUNÇÕES À CRISE IDENTITÁRIA E MAL-ESTAR DO PROFISSIONAL.}

Quando tratamos de identidade, Dubar (1997) ilustra uma teoria sociológica da identidade, assumindo, como ponto inicial, a recusa de uma distinção entre identidade individual e identidade coletiva.

[...] a identidade não é mais do que o resultado simultaneamente estável e provisório, individual e colectivo, subjectivo e objectivo, biográfico e estrutural, dos diversos processos de socialização que, em conjunto, constróem os indivíduos e definem as instituições. (DUBAR, 1997, p. 105)

Seguindo este sentido, a construção das identidades acontece pela ligação entre dois processos identitários heterogêneos, assinalados por Dubar (1997, p. 106) de identidades virtuais. Segundo Teodoro (1998) elas dizem 
respeito à atribuição de identidades pelos agentes e instituições que interagem diretamente com o indivíduo e no qual ele próprio está implicado. Outro processo é o da trajetória vivida, que designa a forma como os indivíduos reconstroem os acontecimentos da sua biografia social que julgam particularmente significativos e relevantes, ambos indicam então de identidades reais.

"O novo aspecto da identidade, promovido através do novo discurso de trabalho da escola e do discurso nacional da competição, é o de que os professores têm de ser disciplinados, obedientes, motivados, responsáveis e sociais" (LAWN, 2001, p.129). O professor está aberto a novas formas de elaboração da identidade e estão a ser produzidos modelos competitivos e diferenciados da identidade do professor.

As instituições de ensino estão inseridas em uma circunstância complexa em profundas e constantes transformações, desencadeando uma crise que, embora venha se desenvolvendo já há algum tempo, tem se agravado ultimamente. Nas concepções de Nóvoa, essa crise nas instituições vem provocando um mal-estar nos professores cujas implicações "estão à vista de todos: desmotivação pessoal e elevado índice de absenteísmo ede abandono, insatisfação profissional traduzida numa atitude de desinvestimento e de indisposição constante" (NÓVOA, 1991, p. 20).

Para abordar sobre a crise de identidade nos papéis e na formação docente adotamos também como referência Esteve (1992) com sua obra ' $O$ mal-estar docente'. O autor faz uma breve comparação entre a realidade docente brasileira com outros países. Disserta sobre o mal-estar do profissional utilizando-se em alguns casos de situações onde há manifestações mais evidentes que no Brasil. Sendo que mesmo diante das constantes transformações ocorridas, o autor ainda enfatiza que somente através da criatividade é que

[...] podem salvar nosso ator e nossos professores do problema que implica a mudança de cenário. Para manter a coerência e recuperar os papéis, precisamos encarar em público os roteiristas, tirar o ponto de seu lugar e a acabar com os risos das pessoas do auditório, pedindo que assumam nosso papel. (ESTEVE, 1999, p. 18)

Neste sentido, fica evidente que autor defende que o professor precisa redefinir o seu papel junto à sociedade, mesmo diante de um ensino 
massificado onde o profissional é constantemente responsabilizado pelo fracasso.

Quando pensamos nos indicadores dessa crise docente tomamos como referência as concepções de Blase (1982), por classificar os fatores em: elementos primários e elementos secundários. O primeiro, também conhecido como elementos principais, incidem diretamente sobre a ação do professor em sala de aula, motivando crises associadas a sentimentos e emoções negativas. O segundo, chamado também de elementos contextuais, relaciona-se às condições ambientais, ao contexto em que está ocorrendo à docência. Neste último fator, Esteve (1999) reforça com a seguinte ponderação:

\begin{abstract}
Esses mecanismos que influenciam a imagem pública do professor nos dão a medida da importância do contexto social em que se exerce a docência para a autorrealização do professor no magistério. A atuação individual não é totalmente independente do contexto social em que se realiza e, em muitas razões, o sentimento de desânimo que domina muitos professores tem suas bases muito mais nesses fatores conceituais, [...] do que na situação real da sala de aula, com todas as suas dificuldades. (ESTEVE, 1999, p. 47)
\end{abstract}

Segundo Wells e Marwell (1976), a forma como uma pessoa se percebe e se avalia, neste caso o coordenador pedagógico em destaque, pode decidir a forma de se relacionar com os outros, as experiências em que confia, as emoções que experimenta e o modo como as compreende. É, portanto perceber e ter autoconceito profissional, que nada mais é, de acordo com Veiga (1996) como a percepção que o indivíduo tem de si próprio como tal e de si mesmo em relação aos demais.

Continuando a questão de autoconceito profissional, um estudo apresentado no VII Congresso Galaico-Português de Psicopedagogia aponta que

\begin{abstract}
Com base nas características da profissão docente e sua evolução, parece legitimo supor-se que o conhecimento de si mesmo e uma maior consciência do eu profissional estarão ligados entre si e com o desempenho, eficácia e motivação para as tarefas; a compreensão do autoconceito profissional pode facilitar a promoção de outras dimensões da personalidade, tais como o relacionamento interpessoal e a satisfação do indivíduo consigo mesmo. (VEIGA, 1996, p. 1020).
\end{abstract}

A desconfiança de uma hipotética crise de identidade profissional como a do coordenador pedagógico insere-se num conflito onde o principal aspecto são as profundas transformações que atingem o mundo do trabalho educativo na sociedade atual. Estas modificações exigem o redimensionamento das 
funções desempenhadas pelo profissional, o que sugere uma crise de identidade.Outra referência que aborda sobre mal-estar gerado pelo trabalho é Lévy-Leboyer (1994), este autor aponta que a função profissional é colocada pela maioria dos indivíduos em segundo plano, apesar de não ser descartada totalmente, principalmente pelas vantagens materiais que são propiciadas; 0 trabalho "não corresponde mais a um desejo unânime, não é mais uma fonte de satisfações e menos ainda uma componente importante da qualidade de vida". (LÉVY-LEBOYER, 1994, p. 20).

Percebe-se o crescimento cada vez mais acentuado de profissionais que estão desistindo de suas áreas profissionais, sendo muitos oriundos da educação. Para Rebolo, esses profissionais

[...] estão fugindo das mazelas de um sistema de ensino que impõe, aos que dele participam, grandes obstáculos para a realização de um trabalho satisfatório e compensador, e que garanta, para além da simples sobrevivência, uma vida saudável e equilibrada. Os dissabores e o desencanto com o trabalho docente podem ser percebidos nas conversas cotidianas dos professores, através das quais manifestam um grande desânimo e uma vontade, expressa na fala de muitos, de 'largar tudo'(REBOLO, 1999, p. 2).

Nesta perspectiva, ainda podemos destacar que o trabalho tem deixado de ocupar um papel central na vida do homem, seja pelo sofrimento vivido, seja pela crise das várias funções muitas vezes exercidas ou por outros desequilíbrios causados com o mal-estar dos profissionais. Outro ponto que não pode ser deixado de considerar é a grande expansão do capitalismo, destacado por Antunes (2006, 2004, 2002), Harvey (1993) e Hirata (2002), pois o movimento concentra novas formas de reestruturação produtiva e, consequentemente, exigindo novos procedimentos de trabalho. $O$ que se percebe atualmente é que

Assiste-se hoje à dupla transformação do trabalho, tanto quanto ao conteúdo da atividade quanto às formas de emprego, transformação aparentemente paradoxal, pois esse duplo processo ocorre em sentidos opostos. De um lado, há a exigência de estabilização, de implicação do sujeito no processo de trabalho, por intermédio de atividades, comunicação ou intercompreensão. Por outro lado, verifica-se um processo de instabilização, precarização dos laços empregatícios, aumento de desemprego prolongado e flexibilidade no uso da força de trabalho. Em duas palavras: perenidade $\mathrm{e}$ superfluidade. E esse movimento é global e mundializado. (ANTUNES, 2004, p. 10) 
No que se refere a algumas relações, o trabalho provoca mais aflição do que satisfação na medida em que passa a atender mais as expectativas dos outros, que nem sempre são as mesmas do próprio profissional.

Evidentemente devemos considerar que a formação de um coordenador pedagógico, e, consequentemente, a construção de sua identidade profissional, resulta de um processo de constituição de múltiplas identidades que influenciam diretamente no fazer profissional. Entretanto, não podemos perder de vista que também existem outros aspectos implicantes desse processo, como é o caso das políticas públicas. $E$ todas possuem influência na constituição do profissional. A seguir vemos como ocorre este processo no estado do Pará.

\section{A CONSTITUIÇÃO DA IDENTIDADE PROFISSIONAL DO COORDENADOR PEDAGÓGICO NO ESTADO DO PARÁ.}

A definição da verdadeira função correspondente ao coordenador pedagógico torna-se mais complexa quando analisamos as causas e os efeitos da falta de clareza e do desvio da sua função. Seja pela sobrecarga de trabalho ou desorganização da rotina de apoio aos professores e outras tarefas mais da área de atuação. Compreendem-se as dificuldades enfrentadas pelo coordenador pedagógico em exercer o seu papel, por conta das múltiplas atribuições a ele conferidas, fica enfatizado que muitas dessas ações não são da sua competência.

Trabalhar com seres humanos exige várias habilidades com as relações sociais e interpessoais existentes na escola, uma vez que se trata de lidar com a complexidade do humano: esse sujeito transformador de $\mathrm{si}$, da realidade (professor), é um sujeito que talvez traga na sua história de vida pessoal e profissional, algumas frustrações, medos, sentimentos de inferioridade, baixa autoestima, insegurança, etc., e que pode ser uma pessoal difícil de relacionarse e resistente a mudanças, é com esse sujeito que o coordenador pedagógico vai precisar saber lidar, conforme está previsto no Art. 7º, XII da Lei № 7.023 , de 23 de janeiro de 1997, em que é atribuição do coordenador pedagógico "promover ações que otimizem as relações interpessoais na comunidade escolar;"; portanto, é necessário que o coordenador esteja preparado para mais 
essa dificuldade que terá de enfrentar no seu dia a dia; por essa razão, é importante que ele conheça cada professor com quem ele trabalha.

Para Paulo Freire "a escola não é boa nem má em si. Depende ao serviço de quem ela está no mundo. Precisa saber a quem ela defende". (FREIRE, 2004, p. 38) e essa relação de conscientização perpassa obrigatoriamente pelo diálogo entre o professor e seu aluno. Esse diálogo deve estar presente em todo o processo educativo, sendo este o caminho para a reflexão de nossos alunos, que através da conscientização política devem questionar a que interesses a educação está servindo.

$\mathrm{Na}$ sua trajetória histórica o coordenador busca formar sua identidade profissional, na luta pela afirmação da estima pelo seu trabalho, o coordenador pedagógico atuou, de acordo com pesquisa de Augusto (2006), como fiscal e atendente, desempenhando função de pouca expressão no processo pedagógico. Entretanto, nos anos 90 o trabalho do coordenador pedagógico mostrou-se mais expressivo. Fernandes (2004) aponta uma trajetória que nos permite evidenciar que em outros momentos onde ocorreram movimentos de inovação pedagógica e de reforma educacional ela também esteve presente.

Desta forma, a presença do coordenador pedagógico está implantada em um contexto contraditório marcado pelo vaivém existente entre as reformas educacionais dos anos 90 e a presença de uma visão progressista de educação, herança dos anos 80.

Dessa forma, a presença do coordenador pedagógico em diferentes momentos na história no período da reforma educacional, revela a importância do trabalho desse profissional no âmbito educacional. As diferentes denominações atribuídas ao coordenador (inspetor, orientador, supervisor, professor coordenador pedagógico, especialista) e a falta de clareza do campo de atuação nas unidades de ensino, são fatores que acompanham a trajetória desse profissional assim como a utilização da sua função como instrumento de manipulação para atender interesse político vigente.

No cotidiano escolar o coordenador pedagógico confronta-se consigo mesmo ao repensar, reavaliar e redirecionar suas ações, além disso, ele confronta-se também com o outro, com sua cultura, seus saberes, suas práticas, seus valores, suas expectativas e desejos. E essas são situações em que o coordenador pedagógico precisa ter muita habilidade para enfrentar. 
Para tanto, o coordenador não pode desprezar no seu trabalho cotidiano a existência das importâncias, das urgências, das rotinas e, sobretudo, das pausas, indispensáveis para reflexão e realimentação do corpo e da mente, para que gerem ações conscientes, significativas e criativas no enfrentamento dos obstáculos e problemas que emergem no trabalho cotidiano.

Isso impõe ao coordenador pedagógico a necessidade de uma gama de saberes para atuar conscientemente nas diversas situações que permeiam 0 espaço escolar, dentre elas destacamos o processo ensino/aprendizagem; o desenvolvimento, implantação e implementação do Projeto Político Pedagógico da Escola; a formação de professores; a utilização de métodos/estratégias e recursos pedagógicos mais adequados para o desenvolvimento dos alunos e a promoção de ações que contribuem para o equilíbrio das relações interpessoais. Esses saberes, inerentes ao coordenador pedagógico, segundo as autoras André e Vieira (2006): saberes gerenciais; saberes profissionais, éticos, políticos; saberes relacionais; saberes curriculares, técnicoprofissionais, afetivos e experienciais. Nesse contexto, salientamos que 0 domínio desses e de muitos outros saberes, torna o coordenador pedagógico hábil para intervir em situações diversas no seu cotidiano.

Portanto, compete ao coordenador pedagógico propor novas atividades que visem o desenvolvimento profissional dos professores. Também é preciso fazer com que haja constantes reflexões da sua prática e o confronto de teorias com base em pesquisas e análises, afinal, é preciso atos efetivos que provoque e inspire os educadores a buscar permanente por sua autoformação.

Nessa perspectiva, entendemos que como agente formador, 0 coordenador pedagógico deve articular todo o processo ensino-aprendizagem, no sentido de promover situações em que a autoformação aconteça, como, grupos de estudos, tematização da prática, recomendação de leituras, promoção de encontros em que os professores possam compartilhar informações e trocar novos conhecimentos adquiridos em cursos, congressos, enfim estimular os professores a serem não só responsáveis por sua autoformação, mas também coparticipantes da formação contínua dos seus pares. Como nos diz Geglio (2006):

O coordenador pedagógico é quem, [...] num espírito de parceria e coletividade, conduz o processo, participa, discute, ouve, orienta, propõe, informa, assume e partilha responsabilidades com os 
professores, indica ações, enfim, exerce uma posição natural de liderança, de autoridade. (GEGLIO, 2006, P. 118).

Essas ações têm a intenção de garantir o aperfeiçoamento do professor e a qualidade do processo de ensino/aprendizagem dentro da escola.

Acreditamos, ainda, que na formação de professores, o coordenador pedagógico deve trabalhar para constituir uma relação de respeito e confiança entre ambos e, para isso, é preciso saber relacionar com as pessoas, e isto envolve o saber ouvir, ver e falar. Nesta perspectiva Almeida (2006) aponta que:

\begin{abstract}
o colocar-se no lugar do outro, é também recurso fundamental para levar ao crescimento. Ser capaz de tomar o lugar de referência do outro, sem, no entanto, esquecer que é do outro, é condição imprescindível a uma relação interpessoal promotora de crescimento. (ALMEIDA, 2006, p. 76)
\end{abstract}

Portanto, neste sentido, o coordenador pedagógico deve sensibilizar seu saber-fazer de maneira a não tomar todas as decisões, como se fosse dotado a responder todas as perguntas de orientações pedagógicas e conflitos que inquietam a equipe de professores. O coordenador pedagógico deve agir constantemente com possibilidade de mudança, e isso deve impulsioná-lo a provocar ações reflexivas e inovadoras de diversas ordens nos professores, sendo que só será possível a partir da formação continuada deste grupo. Portanto, a análise e reflexão da própria prática produzem mudanças nas atitudes, na forma conceitual, levando-os em direção ao equilíbrio entre o ser, o estar sendo e o fazer.

A compreensão do papel do coordenador pedagógico e da organização do trabalho de coordenação pedagógica nas escolas paraenses exige 0 resgate de suas origens, da forma como esse profissional surgiu e da maneira pela qual foi construindo historicamente sua atuação no contexto educacional. Já que a história da coordenação pedagógica no estado do Pará é considerada muito incipiente.

O coordenador pedagógico é um profissional que teve sua formação em nível de graduação no curso de Pedagogia, nas antigas habilitações de orientação educacional e supervisão escolar, que recebe atualmente novas denominações e habilitam às novas funções as exercidas anteriormente. $\mathrm{Na}$ ementa de suas atribuições, percebe-se a tentativa de desatrelar com a 
dicotomia histórica da divisão social do trabalho escolar. Nessa perspectiva, o orientador educacional deveria trabalhar unicamente com o corpo discente e o supervisor, com o corpo docente da instituição de ensino.

Apesar disso, fica claro que o objetivo do trabalho do coordenador pedagógico é a organização do trabalho educativo na instituição de ensino. A função do profissional no contexto escolar se aproxima preponderantemente do trabalho anteriormente exercido pelo supervisor escolar, pela evidência na articulação, auxílio e controle do planejamento e execução das atuações pedagógicas.

Mesmo com a similaridade das atuações e funções exercidas pelo coordenador pedagógico com funções do supervisor escolar, estamos conduzidos a assegurar que a raiz da coordenação pedagógica se encontra no campo da supervisão escolar. Atrelado a essa verificação, soma-se o fato de a literatura educacional, que aborda o tema da supervisão, ter apontado frequentemente a coordenação do ensino como uma função exercida pelo supervisor educacional. Podemos averiguar isso com as concepções de Lacerda quando propõe que "a função do supervisor da educação na escola se concretiza na coordenação e estruturação do trabalho docente, através dos processos administrativos de planejamento, controle e avaliação" (1983,p. 95).

Já com as análises dos estudos de Silva Jr. (1984) são apontadas a coordenação como um dos papéis do supervisor de ensino, e essas, que são exercidas nos mais variados níveis do sistema central, regional e local. Nessas perspectivas, exploraremos um enfoque histórico da supervisão escolar procurando contribuições que possibilitem compreender a constituição do coordenador pedagógico no sistema de ensino.

De acordo com lei $n^{\circ}$ 7.442, de 2 de julho de 2010 que dispõe sobre 0 Plano de Cargos, Carreira e Remuneração dos Profissionais da Educação Básica da Rede Pública de Ensino do Estado do Pará e dá outras providências. Em seu Artigo 2o , fica entendido que são integrantes do quadro permanente dos profissionais da Educação Básica da Rede Pública de Ensino do Estado do Pará os seguintes cargos: Professor; Especialista em Educação; Auxiliar Educacional e Assistente Educacional. Sendo que todas as funções citadas podem ser de profissionais oriundos de cursos de licenciatura em pedagogia. 
No Artigo $4^{\circ}$ da lei $n^{\circ} 7.442$ entende-se que o Magistério Público é o conjunto de cargos ocupados por profissionais da Educação, que exercem atividades de docência e de suporte pedagógico, incluídas as de administração escolar, planejamento, supervisão e orientação educacional, bem como assessoramento técnico e avaliação de ensino e pesquisa.

\section{CONSIDERAÇÕES FINAIS}

O coordenador pedagógico para então agir em processo de parceria na escola, necessita inevitavelmente de uma gama de saberes para atuar conscientemente nas diversas situações que permeiam o espaço escolar, dentre elas destacamos o processo ensino/aprendizagem; o desenvolvimento, implantação e implementação do Projeto Político Pedagógico da Escola; a formação de professores; a utilização de métodos/estratégias e recursos pedagógicos mais adequados para o desenvolvimento dos alunos e a promoção de ações que contribuem para o equilíbrio das relações interpessoais.

Esses saberes, inerentes ao coordenador pedagógico, são das mais primordiais funções que the cabe: saberes gerenciais; saberes profissionais, éticos, políticos; saberes relacionais; saberes curriculares, técnicoprofissionais, afetivos e experienciais. Nesse contexto, salientamos que 0 domínio desses e de muitos outros saberes, torna o coordenador pedagógico hábil para intervir em situações diversas no seu cotidiano escolar.

Portanto, compete ao coordenador pedagógico propor novas atividades que visem o desenvolvimento profissional dos professores, e fazer com que haja constantes reflexões da sua prática e o confronto de teorias com base em pesquisas e análises, afinal, é preciso atos efetivos que provoque e inspire os educadores a buscar permanente por sua autoformação.

Nessa perspectiva, entendemos que esse profissional é como agente formador; articulador; que deve articular todo o processo ensino-aprendizagem, no sentido de promover situações em que a autoformação aconteça, como grupos de estudos, tematização da prática, recomendação de leituras, promoção de encontros em que os professores possam compartilhar 
informações e trocar novos conhecimentos adquiridos em variados eventos de formação, enfim estimular os professores a serem não só responsáveis por sua autoformação, mas também coparticipantes da formação contínua dos seus pares, de seu alunado.

\section{REFERÊNCIAS BIBLIOGRÁFICAS}

ANDRÉ, M. e cols. Estado da arte da formação de professores no Brasil. Educação e Sociedade, 20(68), 301-309, 1999.

ANTUNES, R. Anotações sobre o capitalismo recente e a reestruturação produtiva no Brasil. In: ANTUNES, Ricardo, SILVA, Maria Aparecida Moraes (Org.). O avesso do trabalho. São Paulo: Expressão Popular, 2004. p. 13-27.

ANTUNES, R. Riqueza e miséria do trabalho no Brasil. São Paulo: Boitempo, 2006.

ANTUNES, R. Trabalho, reestruturação produtiva e algumas repercussões no sindicalismo brasileiro. In: ANTUNES, Ricardo. Neoliberalismo, trabalho e sindicatos: reestruturação produtiva no Brasil e na Inglaterra. $2^{\mathrm{a}}$ edição. São Paulo: Boitempo, 2002.p. 71-84.

BAUMAN, Z. Identidade: entrevista a Benedetto Vecchi. Rio de Janeiro: Jorge Zahar, 2005.

BRASIL, Secretaria de Educação Média e Tecnológica. PCN Ensino Médio: Orientações Educacionais complementares aos Parâmetros Curriculares Nacionais. Linguagens, códigos e suas tecnologias. Brasília: Ministério da Educação/Secretaria de Educação Média e Tecnológica, 2002.

BRASIL. Ministério da Educação e do Desporto. Secretaria de Educação Fundamental. Parâmetros curriculares nacionais terceiro e quarto ciclos do ensino fundamental: introdução aos parâmetros curriculares nacionais. Brasília, DF: MEC/SEF, 1998.

BUCCINI, I. C. Identidades de educadoras sociais: trajetórias de vida e formação. Dissertação de Mestrado, Universidade de São Paulo, São Paulo, 2007.

CHRISTOV, L. H. S. Educação continuada: função essencial do coordenador pedagógico. In: ARCHANGELO, A et al. O coordenador pedagógico e a educação continuada. 4⿳亠丷a edição. São Paulo: Loyola, 2001.

CIAMPA, A. C. A estória do Severino e a história da Severina. São Paulo: Editora Brasiliense, 1987.

DUARTE, G. R. Formação de professores para o século XXI: dimensões de uma crise vivenciada. História e Ensino, Londrina, v.11, jul, 2005. 
DUBAR, C. Para uma teoria sociológica da identidade. Em A socialização. Porto: Porto Editora, 1997.

DUBAR, C. A Socialização. Construção das Identidades Sociais e profissionais. Porto: Porto Editora, 1997.

ESTEVE, J. M. Z. O mal-estar docente: a sala de aula e a saúde dos professores. 3a Edição. Bauru: Edusc, 1999.

FERREIRA, M. A. Ser-professor: construção de identidade em processo autoformativo. Dissertação de mestrado, Universidade Metodista de São Paulo, São Bernardo do Campo, São Paulo, 2006.

FREIRE, Paulo. Pedagogia do oprimido. 38. ed. São Paulo: Paz e Terra, 2004.

FREITAS, F. L. A constituição da identidade docente: discutindo a prática no processo de formação. Dissertação de Mestrado, Universidade Estadual de Campinas, Campinas, São Paulo, 2006.

FUSARI, J. C. Formação contínua de educadores na escola e em outras situações. In: BRUNO, E. et al. (Orgs.). O coordenador pedagógico e a formação docente. $2^{\mathrm{a}}$ Edição. São Paulo: Loyola, 2001.

FUSARI, J. C. Formação contínua de educadores: um estudo de representações de coordenadores pedagógicos da Secretaria Municipal de Educação de São Paulo. Tese (Doutorado). Faculdade de Educação da Universidade de São Paulo, São Paulo, 1997.

GARRIDO, E. Espaço de formação continuada para o professor-coordenador. In: BRUNO, E. B. G.; ALMEIDA, L. R.; CHRISTOV, L. H. S. O coordenador pedagógico e a formação docente. $2^{\mathrm{a}}$ edição. São Paulo: Loyola, 2001.

GIL, A. C. Como elaborar projetos de pesquisa. 3ª edição. São Paulo: Altas. 1991.

HALL, S. A identidade cultural na pós-modernidade. 11ª Edição. São Paulo: DP \& A, 2006.

HARVEY, D. A condição pós-moderna. São Paulo: Loyola, 1993.

HIRATA, H. Nova divisão sexual do trabalho? Um olhar voltado para a empresa e a sociedade. São Paulo: Boitempo, 2002.

LACERDA, M. C. Configuração da percepção do supervisor educacional em relação ao papel social e político que ele exerce junto aos professores. 1983. Dissertação (Mestrado) - Pós-Graduação em Educação, Universidade Estadual de Campinas, Campinas. 
LAWN, M. Os professores e a fabricação de identidades. Currículo sem Fronteiras, v.1, n.2, pp. 117-130, Jul/Dez 2001.

LÉVY-LEBOYER, C. A crise das motivações. São Paulo: Atlas, 1994.

LIBÂNEO, J. C. Adeus Professor, Adeus Professora? Novas exigências educacionais e profissão docente. $2^{\underline{a}}$ edição. São Paulo: Cortez, 1998 a.

LIBÂNEO, J. C. et al. Educação escolar: políticas, estrutura e organização. São Paulo: Cortez, 2003.

LIBÂNEO, J. C. Fundamentos Teóricos e Práticos do Trabalho Docente Estudo Introdutório Sobre Pedagogia e Didática. Tese de Doutorado. PUCSP/ 1990.

LIBÂNEO, J. C. Organização e gestão da escola: teoria e prática. $5^{\text {a }}$ Edição. Goiânia: Alternativa, 2004.

LIBÂNEO, J. C. Pedagogia e pedagogos, para quê? São Paulo: Cortez, 1999.

LIBÂNEO, J. C. Que destino os educadores darão à Pedagogia? In: PIMENTA, S. G. (Coord.). Pedagogia, ciência da educação? São Paulo: Cortez, 1998b.

LIBÂNEO, J. C. O sistema de organização e gestão da escola. In. LIBÂNEO, J. C. Organização e Gestão da Escola: teoria e prática. 4a Edição. Goiânia: Alternativa, 2001.

LIBÂNEO, J. C; OLIVEIRA, J. F; TOSCHI, M. S. Educação Escolar: políticas, estrutura e organização. São Paulo: Cortez, 2003.

NÓVOA, A. As ciências da educação e os processos de mudança. In: PIMENTA, Selma G. Pedagogia, ciência da educação? 2 ${ }^{a}$ Edição. São Paulo: Cortez, 1998.

NÓVOA, A. Nova Escola. oํ 142. São Paulo: abril, maio 2001.

NÓVOA, A. O Passado e o Presente dos Professores. In: NÓVOA, António (Org.). Profissão Professor. Porto: Porto Editora, 1991 a. p. 9-32.

NÓVOA, A. Os Professores: Quem são? Donde vêm? Para onde vão? In: STOER, S. R. (Org.). Educação, ciências sociais e realidade portuguesa. Porto: Edições Afrontamento, 1991b. p. 59-130.

ORSOLON, L. A. M. Trabalhar com as famílias: uma das tarefas da coordenação. In PLACCO, V. N. S.; ALMEIDA, L. R de (orgs.). O coordenador pedagógico e o cotidiano da escola. São Paulo: Edições Loyola.

PANDOLPHO, M. M. S. (2006). Ensino de Biologia em questão: os valores e as referências da graduação na prática docente sob o olhar de 
egressos. Dissertação de Mestrado, Pontifícia Universidade Católica de Campinas, Campinas, São Paulo.

PARO, V. H. Por dentro da escola pública. 3를 Edição. São Paulo: Xamã, 2000.

PIMENTA, S. G. Professor reflexivo: construindo uma crítica. In: PIMENTA, S. G.; GHEDIN, E. G. (Orgs.) Professor reflexivo no Brasil: gênese e crítica de um conceito. São Paulo: Cortez, 2002. p. 17-52.

PIMENTA, S. G.; ANASTASIOU, L. das G. C. Docência no ensino superior. São Paulo: Ed. Cortez, 2002. p. 279. (Coletânea Docência em Formação: Ensino Superior).

PIMENTA, S. G.; ANASTASIOU, L. das G. C.; CAVALLET, V. J. Docência no ensino superior: construindo caminhos. In: PIMENTA, S. G. De professores, pesquisa e didática. Campinas: Papirus, 2002. p. 129-144. (Coleção Entre Nós Professores).

POLATO, A. Como atua o trio gestor. In. FUNDAÇÃO VICTOR CIVITA. Nova Escola Gestão Escolar, edição 006, fevereiro/março, 2010. Disponível em: $\quad<$ http://revistaescola.abril.com.br/gestao-escolar/diretor/como-atua-triogestor-diretor-escolar-supervisor-ensino-supervisao-coordenacao-pedagogicacoordenador-532548.shtml?page=0 > Acesso ago. 2021.

SAVIANI, D. A supervisão educacional em perspectiva histórica: da função à profissão pela mediação da ideia. In: FERREIRA, N. S. C. (org.) Supervisão educacional para uma escola de qualidade: da formação a ação. $3^{\mathrm{a}}$ edição. São Paulo: Cortez, 2002.

SAVIANI, N. Função Técnica e Função Política da Supervisão em Educação. 1981. Dissertação (Mestrado) - Pós-Graduação em Educação, Pontifícia Universidade Católica de São Paulo, São Paulo.

SCHNEIDER, M. P; DURLI, Z. Ensino fundamental de nove anos: aspectos legais e didático - pedagógicos. Roteiro - Revista da Universidade do Oeste de Santa Catarina, v. 34, n. 2, p. 121 -320, jul./dez. 2009.

SILVA JR, C. A. da. Supervisão da educação: do autoritarismo ingênuo à vontade coletiva. São Paulo, SP: Edições Loyola, 1984.

SILVA JR, C. A. da; RANGEL, Mary (orgs.). Nove olhares sobre a supervisão. 9a Edição. Campinas, SP: Papirus, 2003.

SILVA JR., J. dos R. Reforma do Estado e da educação no Brasil de FHC. São Paulo: Xamã, 2002.

SILVA, I. C. F. A (Re) invenção da municipalização do Ensino: o avesso e o direito na representação social dos responsáveis pela gestão do ensino fundamental público no Município. 2003. Tese (Doutorado) - Programa de Pós-Graduação em Educação, Universidade Estadual de Campinas, Campinas. 
SILVA, N. S. F. C. da.O papel do supervisor no atual contexto brasileiro. Caderno CEDES. Campinas (7): 6-17, 1983.

SILVA, N. S. F. C. da. Supervisão educacional: uma reflexão crítica. Petrópolis: Vozes, 1981.

TEODORO, A. Crise de identidade nos papéis e na formação de professores. Mesa Redonda; XIV Congresso Mundial de Sociologia, Montréal, Julho - Agosto de 1998.

VEIGA, F. H. Autoconceito profissional dos professores: Construção de uma escala de avaliação. Estudo apresentado no VII Congresso GalaicoPortuguês de Psicopedagogia, realizado em 24, 25 e 26 de Setembro de 2003, pela Universidade do Minho e pela Universidade da Corunha. Corunha: Universidade da Corunha.

VEIGA, F. H. Transgressão e autoconceito dos jovens na escola: Investigação diferencial. Lisboa. Fim de Século Edições, 1996.

WELLS, E. L.; MARWELL, G. Self-esteem: Its conceptualisation and measurement. London: Sage, 1976. 